\title{
Different effects of heating and freezing treatments on the antioxidant properties of broccoli, cauliflower, garlic and onion. An experimental in vitro study
}

\author{
Hikmet Can Çubukçu', Nazlı Seda Durak Kılıçaslan", ilker Durak"'I \\ Department of Medical Biochemistry, Ankara Üniversitesi Tip Fakültesi, Ankara, Turkey
}

'MD. Medical Biochemistry Specialist, Department of Medical Biochemistry, Mareşal Çakmak Devlet Hastanesi, Erzurum, Turkey.

(D) orcid.org/0000-0001-5321-9354

"MSc. Research Assistant, Department of Field Crops, Ankara Üniversitesi Ziraat Fakültesi, Ankara, Turkey.

(D) orcid.org/0000-0001-7221-3572

I'PhD. Professor, Department of Medical Biochemistry, Ankara Üniversitesi Tıp Fakültesi, Ankara, Turkey.

(D) orcid.org/0000-0003-2962-4370

KEY WORDS:

Brassica.

Garlic.

Onions.

Antioxidants.

\begin{abstract}
BACKGROUND: Vegetables have some beneficial effects on human health due to their antioxidant compounds, like polyphenols. Cooking leads to many physical and chemical changes to plant structure that can alter the phytochemical compounds of vegetables.

OBJECTIVES: To investigate the effects of heat treatment and freezing on the antioxidant properties of garlic, onion, broccoli and cauliflower.

DESIGN AND SETTING: Experimental in vitro study in a university laboratory.

METHODS: Fresh broccoli (Brassica oleracea var. italica), cauliflower (Brassica oleracea var. botrytis), garlic (Allium sativum) and onion (Allium cepa) were obtained from a local store. These vegetables were divided into three treatment groups: raw, heated and frozen. The heat treatment consisted of heating them in a drying oven at $150^{\circ} \mathrm{C}$ for 20 minutes. The freezing treatment consisted of keeping them frozen at $-20^{\circ} \mathrm{C}$ until analysis. The total phenolic content, antioxidant activity and malondialdehyde levels of the vegetables were measured using the Folin-Ciocalteu phenol reagent, 2,2-diphenyl-1-picrylhydrazyl radical scavenging activity and thiobarbituric acid reactive substances, respectively.

RESULTS: Heat treatment had deleterious effects on the antioxidant properties of onion and garlic; and it decreased the antioxidant activity of broccoli. Freezing improved the antioxidant activity of broccoli and garlic, but had detrimental effects for cauliflower and onion.

CONCLUSIONS: Heat treatment and freezing exhibit different effects on the antioxidant properties of broccoli, cauliflower, garlic and onion. Convenient cooking and storage patterns should be identified for each vegetable, to obtain the best nutritional benefit from the antioxidant compounds of vegetables.
\end{abstract}

\section{INTRODUCTION}

Consumption of fruits and vegetables is associated with reduced risks of hypertension, stroke, coronary heart disease, cancer, dementia and type 2 diabetes mellitus. ${ }^{1}$ The beneficial effects of vegetables and fruits are attributed to presence of certain bioactive compounds, like polyphenols. Flavonoids, phenolic acids, lignins and stilbenes are polyphenols that exhibit antioxidant effects. ${ }^{2}$

Broccoli (Brassica oleracea var. italica) is a member of the Cruciferous family. ${ }^{3}$ Glucosinolates, flavonoids, cinnamic acid derivatives, carotenoids, ascorbic acid, xanthophylls and minerals are among the substances that broccoli contains. The anticarcinogenic, antimutagenic and antioxidant properties of these compounds contribute to the health benefits from broccoli. ${ }^{4}$

Cauliflower (Brassica oleracea var. botrytis L.) is also included in the Cruciferous family. The components of cauliflower include glucosinolates, ascorbic acid, carotenoids, phenolic compounds and vitamin E. ${ }^{3}$ It has anticarcinogenic and antioxidant effects, like other cruciferous vegetables. ${ }^{5,6}$

Garlic (Allium sativum) has been consumed as a vegetable and natural remedy for centuries. ${ }^{7}$ In addition to organosulfur compounds, garlic contains high amounts of vitamins, minerals and phenolic compounds. So far, garlic has been reported to have anticancer, antimicrobial, antioxidant, anti-inflammatory, immunomodulatory and cardioprotective properties. ${ }^{8}$

Onion (Allium cepa L.) is cultivated in many parts of the world, given its adaptable nature. Flavonoids and alk(en)yl cysteine sulfoxides are the main bioactive groups in onion, and these compounds are responsible for antithrombotic, antiasthmatic, anticarcinogenic, antioxidant, antifungal and antibacterial effects. ${ }^{9}$ 
Most vegetables are consumed after a cooking procedure that may involve boiling, microwaving, steaming or baking. Cooking can lead to many physical and chemical changes in plant structure. The concentration of phytochemical compounds in vegetables can be increased through the matrix softening effect and improved extractability. Conversely, heat treatment can cause thermal degradation of these nutrients. ${ }^{10}$ The antioxidant activity of vegetables is mainly based on their phytochemical compounds, like polyphenols. Cooking can trigger not only oxidation of these compounds, but also leakage of water-soluble compounds. Nevertheless, inactivation of prooxidant enzymes through heat treatment can result in enhanced antioxidant activity. ${ }^{11}$ Additionally, partially oxidized polyphenols can have higher antioxidant activity than the non-oxidized form. Moreover, heat treatment can generate more potent antioxidant products called Maillard reaction products. ${ }^{12}$

Fresh vegetables are preferably stored in a refrigerator or freezer because they only remain fresh for a short time. However, freezing can also impair the nutritional quality of some vegetables. ${ }^{13}$

\section{OBJECTIVE}

The aim of this study was to investigate the effects of heat treatment and freezing on the antioxidant properties of garlic, onion, broccoli and cauliflower by analyzing total phenolic content, antioxidant activity and malondialdehyde levels.

\section{METHODS}

\section{Chemicals used}

Methanol, ethanol, trichloroacetic acid, disodium hydrogen phosphate, potassium dihydrogen phosphate and sodium carbonate were purchased from Merck (Darmstadt, Germany). 2-thiobarbituric acid, 2,2-diphenyl-1-picrylhydrazyl, FolinCiocalteu phenol reagent and gallic acid were purchased from Sigma-Aldrich (Steinheim, Germany).

\section{Vegetables and sample preparation}

Fresh broccoli (Brassica oleracea var. italica), cauliflower (Brassica oleracea var. botrytis), garlic (Allium sativum) and onion (Allium сера) were obtained from a local store. Each vegetable was divided into three treatment groups: raw, heated and frozen.

The heat treatment consisted of heating the vegetables in a drying oven at $150^{\circ} \mathrm{C}$ for 20 minutes. After the heat treatment, the vegetables were stored at $4^{\circ} \mathrm{C}$ for 12 hours in contact with air until analysis. The freezing treatment consisted of keeping the vegetables frozen at $-20^{\circ} \mathrm{C}$ until the time of analysis. The raw vegetables consisted of fresh vegetables stored at $4{ }^{\circ} \mathrm{C}$ in a sterile container in the refrigerator. A sample of 10 grams of each vegetable was used for analysis.

After heating and freezing treatment, the vegetables were homogenized in distilled water using the DIAX 900 homogenizer
(Heidolph, Kelheim, Germany) just before analysis, to make an aqueous extract at a concentration of $10 \%(w / v)$. After centrifugation at $4000 \mathrm{~g}$ for 10 minutes, the supernatant fractions of the homogenates were isolated for analysis.

\section{Measurement of malondialdehyde levels}

Malondialdehyde (MDA) levels were measured spectrophotometrically by using the thiobarbituric acid reactive substances (TBARS) method. This is based on the interaction between thiobarbituric acid (TBA) and MDA in an acidic solution to yield a pink-colored dye. ${ }^{14}$ One $\mathrm{ml}$ of a solution of ethanol (95\%; v/v), phosphate buffer, trichloroacetic acid (20\%; w/v) and thiobarbituric acid (2\%; w/v) was added to each $0.1 \mathrm{ml}$ of the sample in a tube. After 30 minutes of incubation in boiling water, the tubes were centrifuged at $4^{\circ} \mathrm{C}$ in a Harrier 18/80 centrifuge (MSE, London, UK). The absorbances of the clear supernatant fractions were measured spectrophotometrically at $532 \mathrm{~nm}$ by means of a Helios Alpha ultraviolet/visible spectrophotometer (Unicam, Cambridge, UK).

\section{Analysis of antioxidant activity}

The antioxidant activity levels of the vegetables were determined according to their 2,2-diphenyl-1-picrylhydrazyl (DPPH) radical scavenging activity. ${ }^{15} 975 \mu$ of methanolic DPPH solution was added to each $25 \mu \mathrm{l}$ sample in a tube. Following incubation for 30 minutes in the dark, the decline in absorbance was measured at $517 \mathrm{~nm}$ spectrophotometrically, against a negative control. Antioxidant activity was expressed as the percentage DPPH depletion. ${ }^{16}$

\section{Determination of total phenolic content}

The total phenolic content of the vegetables was determined using the Folin-Ciocalteu phenol reagent, as described by Obanda and Owuor. ${ }^{17}$ Briefly, $0.5 \mathrm{ml}$ of Folin-Ciocalteu phenol reagent was mixed with $0.5 \mathrm{ml}$ of the aliquot. After incubation for 5 minutes, $1 \mathrm{ml}$ of $\mathrm{Na}_{2} \mathrm{CO}_{3}$ and $1 \mathrm{ml}$ of water were added to the mixture. Following a further 30 minutes of incubation, the blue-colored end product was measured spectrophotometrically at $700 \mathrm{~nm}$.

\section{Statistical analysis}

The data analyzed in this study were obtained from ten repetitions and were evaluated using the Statistical Package for the Social Sciences (SPSS), version 11.5. Multiple comparisons of the experimental groups were analyzed using the ANOVA and Kruskal-Wallis tests. Tukey's honestly significant difference (HSD), Tamhane's and Dunn's tests were used for post-hoc evaluation of subgroups, where suitable. The relationships between biochemical parameters were assessed using Spearman and Pearson correlation tests. The statistical significance level was taken to be $\mathrm{P}$ values less than 0.05 . 


\section{RESULTS}

The freezing and heat treatments had different effects on the antioxidant activity, phenolic content and MDA levels of the vegetables, as shown in Table 1 and Figures 1-4. All treatments were compared with raw vegetables.

Although the freezing treatment increased the antioxidant activity levels of broccoli and garlic, those of cauliflower and onion declined after this treatment. The phenolic contents of broccoli and cauliflower were enhanced through freezing, while the phenolic content of onion was reduced. Nevertheless, the MDA levels of frozen vegetables were found to be higher than those of raw vegetables.
Even though the heat treatment increased the antioxidant activity of broccoli, the antioxidant activity levels of heated garlic and onion were found to be lower than those of raw garlic and onion. Furthermore, the phenolic content of garlic, onion and cauliflower decreased through the heat treatment. Although the MDA concentration in onion was increased through the heat treatment, there were no statistically significant differences between raw and heated broccoli, cauliflower and garlic.

In addition to the low positive correlation between the phenolic content and antioxidant activity levels of onion $(r=0.467$, $\mathrm{P}<0.01)$ and broccoli $(\mathrm{r}=0.412, \mathrm{P}<0.05)$, a moderate positive

Table 1. Comparisons of the 2,2-diphenyl-1-picrylhydrazyl (DPPH) radical scavenging activity, phenolic compounds and malondialdehyde levels of raw, frozen and heated vegetables

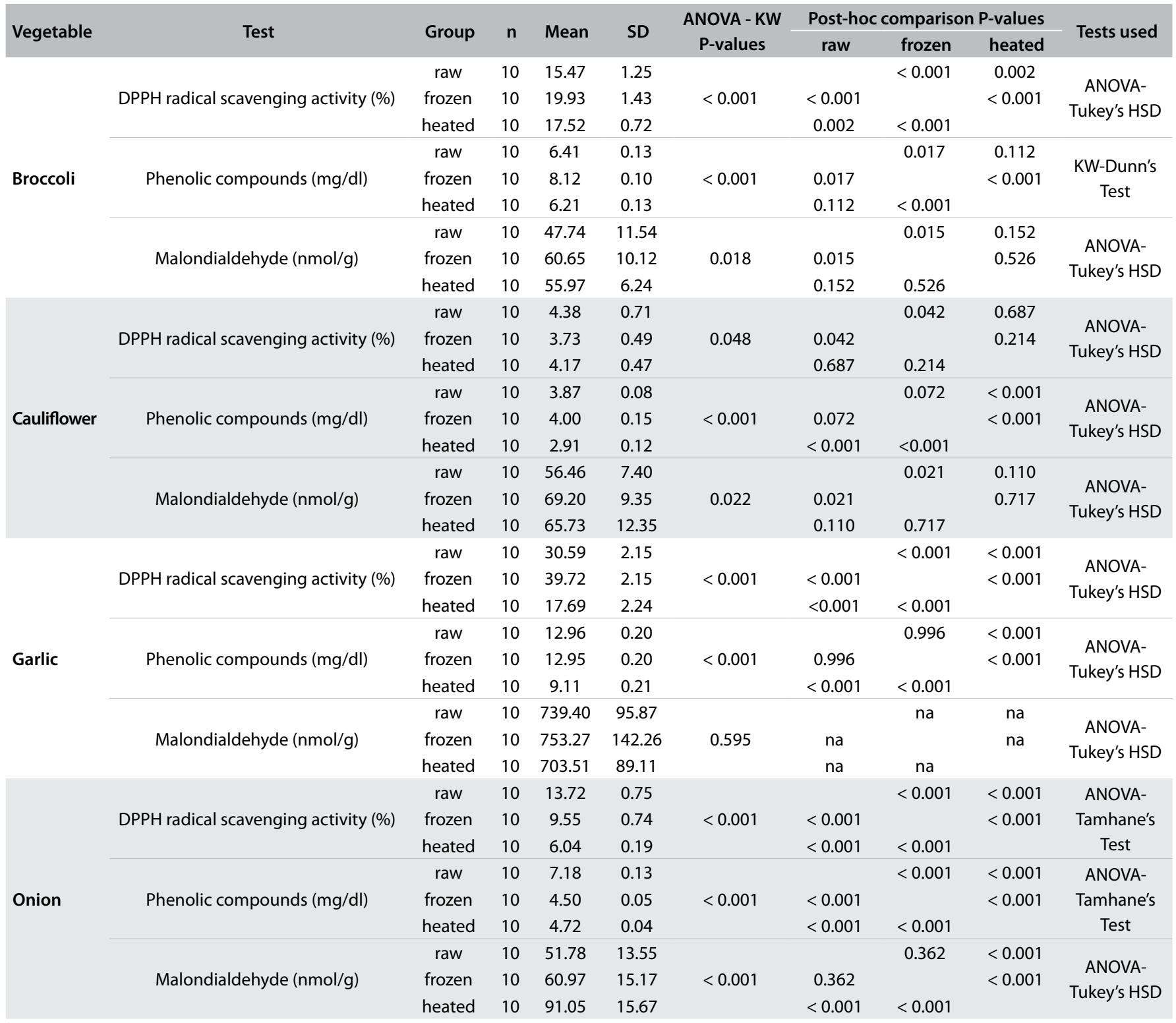


correlation was observed between the phenolic content and antioxidant activity of garlic $(r=0.639, \mathrm{P}<0.01)$. Even though the antioxidant activity levels of onion $(\mathrm{r}=-0.644, \mathrm{P}<0.01)$ and cauliflower $(\mathrm{r}=-0.381, \mathrm{P}<0.05)$ showed negative correlations with their MDA levels, the antioxidant activity of broccoli showed a significantly low positive correlation with MDA level $(r=0.422$, $\mathrm{P}<0.05$ ), as shown in Table 2.

\section{DISCUSSION}

The effects of heat treatment on broccoli, cauliflower, onion and garlic were investigated in the present study. The heat treatment that was applied was analogous to baking.

The present study revealed that heat treatment led to an increase in the antioxidant activity of broccoli, while its total phenolic content was stable during this process $(\mathrm{P}=0.002$ and $\mathrm{P}=0.112$ respectively). Additionally, the malondialdehyde levels remained unchanged during the treatment.

The cooking methods on this topic that were previously studied have mainly approximated boiling, microwaving and steaming. Pellegrini et al. reported that boiling and oven-steaming caused increases in the total phenolic content and antioxidant capacity of fresh broccoli, while microwaving did not. ${ }^{18}$ In contrast to these findings, Zhang and Hamauzu indicated that microwaving and boiling both led to reduction of the total phenolic content, total carotenoids, ascorbic acid levels and antioxidant activity of fresh broccoli. ${ }^{19}$ To our knowledge, the impact of baking on broccoli had not previously been investigated. The heat treatment used in the present study is commonly used in baking. The increased antioxidant activity established in the present study may have been due to enhanced extractability of antioxidants other than phenolics, like $B$-carotene. This is in line with data from a previous study that demonstrated that the $ß$-carotene isomer was released through cooking. ${ }^{20}$

The contradictory data in the literature regarding cauliflower mainly focused on certain cooking methods, including boiling, steaming, microwaving and sous vide (cooking under vacuum). Volden et al. noticed that boiling, blanching and steaming had all detrimental effects on total phenolic content, ascorbic acid levels and antioxidant activity. ${ }^{21}$ Reis et al. stated that while microwaving had no effect on the phenolic content of cauliflower, boiling, steaming and sous vide led to reductions of phenolic compounds. Additionally, antioxidant activity was only increased through microwaving. ${ }^{22}$ Girgin and El demonstrated that steaming caused increases in total phenolic content and antioxidant activity, but that boiling caused reduced levels. ${ }^{23}$

As far as we know, the present study is the first to examine the effects of baking on cauliflowers' antioxidant properties. Heated cauliflower showed lower total phenolic content than raw cauliflower, as shown in Table 1. However, the antioxidant activity of cauliflower seems to be more stable, possibly because of great retention of antioxidant compounds other than phenolic compounds.

We demonstrated that heat treatment had a reducing effect on the phenolic content and antioxidant activity of garlic. Likewise, Park et al. noticed that the DPPH radical scavenging activity and total phenolic content of raw garlic extract were higher than those of heated garlic extract. ${ }^{24}$ A positive relationship between the phenolic content and antioxidant activity of garlic was found in our study ( $\mathrm{r}=0.639, \mathrm{P}<0.01)$. Hence, it could be hypothesized that deterioration of antioxidants, including phenolic compounds, led to the decrease in antioxidant activity.

In our study, the total phenolic content of onion was decreased through heat treatment. To date, contradictory results regarding

Table 2. Correlations between the 2,2-diphenyl-1-picrylhydrazyl (DPPH) radical scavenging activity, phenolic compounds and malondialdehyde levels of vegetables

\begin{tabular}{|c|c|c|c|c|}
\hline \multirow[b]{2}{*}{ Vegetable } & \multirow[b]{2}{*}{ Test } & \multicolumn{3}{|c|}{ Correlation coefficient ( $r$ ) } \\
\hline & & $\begin{array}{c}\text { DPPH radical scavenging } \\
\text { activity (\%) }\end{array}$ & Phenolic compounds (mg/dl) & Malondialdehyde $(\mathrm{nmol} / \mathrm{g})$ \\
\hline \multirow{2}{*}{ Broccoli } & DPPH radical scavenging activity (\%) & & $0.412^{*}$ & $0.422^{*}$ \\
\hline & Malondialdehyde (nmol/g) & $0.422^{*}$ & 0.309 & \\
\hline Cauliflower & DPPH radical scavenging activity (\%) & & -0.200 & $-0.381^{*}$ \\
\hline \multirow{3}{*}{ Garlic } & DPPH radical scavenging activity (\%) & & $0.639^{* *}$ & 0.115 \\
\hline & Phenolic compounds (mg/dl) & $0.639^{* *}$ & & 0.112 \\
\hline & Malondialdehyde (nmol/g) & 0.115 & 0.112 & \\
\hline \multirow[b]{2}{*}{ Onion } & DPPH radical scavenging activity (\%) & & $0.467^{* *}$ & $-0.644^{* *}$ \\
\hline & Phenolic compounds (mg/dl) & $0.467^{* *}$ & & -0.254 \\
\hline
\end{tabular}

${ }^{*} \mathrm{P}<0.05 ;{ }^{* * P}<0.01$. 
alteration of phenolic content have been reported in the literature. Although microwave heating was found to increase the concentration of quercetin, possibly through facilitating extractability, reduced flavonoid content was observed in boiled onion, possibly due to transition to water. ${ }^{25}$ Quercetin glycosides, which are the main flavonoids of onion, can undergo thermal degradation. Rohn et al. showed that quercetin diglucosides were converted to quercetin monoglucosides and quercetin aglycone through roasting. ${ }^{26}$

Reduced flavonoid content in onion was detected when frying, sautéing, boiling, steaming and microwaving treatments were applied. However, baking for 5 minutes at $200{ }^{\circ} \mathrm{C}$ did not show any effects on the flavonoid content of onion, as indicated in the same study. ${ }^{27}$ On the contrary, the quercetin diglucoside and quercetin glucoside concentrations in onion were decreased through heat treatment that was maintained for longer than 10 minutes. ${ }^{28}$ The discrepancy might be attributable to the variety of heat treatment, the degree of applied heat and its duration. Our results are in agreement with the study by Harris et al. ${ }^{28}$ Not only the phenolic content but also the antioxidant activity of onion decreased through heat treatment (Table 1). Furthermore, a positive correlation was observed between the phenolic content and antioxidant activity (Table 2). These results might be explained by the fact that the antioxidant activity of onion is attributable to its phenolic content. Additionally, the increase in malondialdehyde levels showed that the oxidation process induced by heat treatment led to degradation of antioxidant ingredients.

The effects of consumer storage conditions on broccoli, cauliflower, garlic and onion were investigated in the current study. It should be borne in mind that the group of raw vegetables was stored in a refrigerator at $4{ }^{\circ} \mathrm{C}$ to mimic consumer routines.

Frozen broccoli was found to contain higher antioxidant activity, total phenolic content and malondialdehyde levels, compared with raw broccoli. According to our findings, frozen storage preserves the antioxidant compounds of broccoli better than does raw storage.

Divergent results have been reported in the literature. Li et al. stated that the trans beta-carotene and folate levels of broccoli decreased through freezing, while the ascorbic acid levels did not change. ${ }^{29}$ Patras et al. indicated that the antioxidant activity and ascorbic acid levels of unblanched frozen broccoli were lower than those of fresh and blanched frozen broccoli. No significant difference in phenol concentration was observed between the study groups. ${ }^{30}$ Conversely, slightly increased phenolic content was reported for two broccoli cultivars. The total carotenoid concentrations of frozen broccoli cultivars were higher than those of raw ones. ${ }^{31}$ These conflicting findings may have been due to variation in the cultivars studied. Furthermore, vegetables were blanched prior to freezing in some studies.

Frozen cauliflower showed lower antioxidant activity in the present study. Moreover, its malondialdehyde levels increased with freezing. However, no significant change was detected in its total phenolic content. These findings might be explained by the reduction in antioxidants through freezing. These decreased antioxidant levels would thus be due to decrease in the levels of some compounds other than phenolics. Murcia et al. showed that freezing did not significantly affect the antioxidant capacity of cauliflower. ${ }^{32}$ Additionally, Li et al. did not find any statistically significant differences in trans beta-carotene and ascorbic acid levels between frozen and raw cauliflower. ${ }^{29}$ In contrast with previous studies, Volden et al. reported that total phenolic content, L-ascorbic acid levels and antioxidant capacities of some cauliflower cultivars were reduced through freezing. ${ }^{33}$ Our results are partially in agreement with the latter study. In addition to decreased antioxidant activity and increased malondialdehyde levels, we also observed a negative correlation between these two parameters $(r=-0.381)$. It can be inferred from our findings that freezing may somehow lead to an oxidation process in cauliflower.

Frozen storage maintained the antioxidant activity of garlic better than raw storage. However, the freezing process did not give rise to any change in total phenolic content or malondialdehyde levels. Thus, the increased antioxidant activity could be attributable to preservation of antioxidants other than phenolic compounds. Murcia et al. claimed that freezing had a detrimental effect on the antioxidant activity of garlic. However, in Murcia's study, frozen vegetables were separately purchased from a supermarket as commercially processed vegetables. ${ }^{32}$ Therefore, the low quality of the study design makes it hard to come to an accurate conclusion.

In the present study, the phenolic content and antioxidant activity of frozen onion were found to be lower than those of raw onion. On the other hand, the malondialdehyde concentration did not change through freezing, as shown in Table 1. Nimfali and Bacchiocca found that the oxygen radical absorbance capacity and phenolic content were higher in frozen onion than in raw onion. Nevertheless, according to those authors, addition of ascorbic acid for preservation of the packaged product interfered with the analysis. ${ }^{34}$ In contrast to the previous study, our results showed that frozen storage did not possess the essential conditions for preserving the antioxidant properties of onion.

\section{CONCLUSION}

Heat treatment showed deleterious effects on the antioxidant properties of onion and garlic. Conversely, the antioxidant activity of broccoli was enhanced through heat treatment. These findings suggest that thermal degradation of antioxidants may occur in some vegetables, while the antioxidant activity can increase through the improved extractability and matrix softening effects of heat treatment.

Freezing can improve the extractability of the antioxidant compounds of some vegetables like broccoli and garlic. On the other hand, frozen storage did not exhibit convenient conditions 
for preserving the antioxidant properties of cauliflower and onion. Additionally, the increased malondialdehyde levels of cauliflower may somehow have been a result caused by the increased oxidation process due to freezing.

Further research should be undertaken to establish what the most favorable vegetable consumption and storage patterns would be, to obtain the best benefit from the antioxidant compounds of vegetables.

\section{REFERENCES}

1. Boeing $\mathrm{H}$, Bechthold A, Bub A, et al. Critical review: vegetables and fruit in the prevention of chronic diseases. Eur J Nutr. 2012;51(6):637-63. PMID: 22684631; doi: 10.1007/s00394-012-0380-y.

2. Pandey KB, Rizvi SI. Plant polyphenols as dietary antioxidants in human health and disease. Oxid Med Cell Longev. 2009;2(5):270-8. PMID: 20716914; doi: 10.4161/oxim.2.5.9498.

3. Podsędek A. Natural antioxidants and antioxidant capacity of Brassica vegetables: A review. LWT-Food Science and Technology. 2007;40(1):111. doi: 10.1016/j.lwt.2005.07.023.

4. Latté KP, Appel KE, Lampen A. Health benefits and possible risks of broccoli - An overview. Food Chem Toxicol. 2011;49(12):3287-309. PMID: 21906651; doi: 10.1016/j.fct.2011.08.019.

5. Hodges DM, Munro KD, Forney CF, Mcrae KB. Glucosinolate and free sugar content in cauliflower (Brassica oleracea var. botrytis cv. Freemont) during controlled-atmosphere storage. Postharvest Biology and Technology. 2006;40(2):123-32. doi: 10.1016/j.postharvbio.2005.12.019.

6. Llorach R, Espín JC, Tomás-Barberán FA, Ferreres F. Valorization of cauliflower (Brassica oleracea L. var. botrytis) by-products as a source of antioxidant phenolics. J Agric Food Chem. 2003;51(8):2181-7. PMID: 12670153; doi: 10.1021/jf021056a.

7. Rivlin RS. Historical perspective on the use of garlic. J Nutr. 2001;131(3s):951S-4S. PMID: 11238795; doi: 10.1093/jn/131.3.951S

8. Martins NS. Petropoulos IC. Ferreira, Chemical composition and bioactive compounds of garlic (Allium sativum L.) as affected by preand post-harvest conditions: A review. Food Chem. 2016.211:41-50. PMID: 27283605; doi: 10.1016/j.foodchem.2016.05.029.

9. Griffiths G, Trueman L, CrowtherT, Thomas B, Smith B. Onions - A global benefit to health. Phytother Res. 2002;16(7):603-15. PMID: 12410539; doi: 10.1002/ptr.1222.

10. Palermo M, Pellegrini N, FoglianoV. The effect of cooking on the phytochemical content of vegetables. J Sci Food Agric. 2014;94(6):105770. PMID: 24227349; doi: 10.1002/jsfa.6478.

11. Murador D, Braga AR, Da Cunha D, De Rosso V. Alterations in phenolic compound levels and antioxidant activity in response to cooking technique effects: A meta-analytic investigation. Crit Rev Food Sci Nutr. 2018.58(2):169-77. PMID: 26858038; doi: 10.1080/10408398.2016.1140121

12. Nicoli MC, Anese M, Parpinel M. Influence of processing on the antioxidant properties of fruit and vegetables. Trends in Food Science \&Technology. 1999;10(3):94-100. doi: 10.1016/S0924-2244(99)00023-0.
13. Giannakourou MC, Taoukis PS. Kinetic modelling of vitamin C loss in frozen green vegetables under variable storage conditions. Food Chem. 2003;83(1):33-41. doi: 10.1016/S0308-8146(03)00033-5.

14. Dahle LK, Hill EG, Holman RT. The thiobarbituric acid reaction and the autoxidations of polyunsaturated fatty acid methyl esters. Arch Biochem Biophys. 1962;98(2):253-61. doi: 10.1016/0003-9861(62)90181-9.

15. Brand-Williams W, Cuvelier ME, Berset C. Use of a free radical method to evaluate antioxidant activity. LWT - Food Science and Technology. 1995;28(1):25-30. doi: 10.1016/S0023-6438(95)80008-5.

16. Chrzczanowicz J, Gawron A, Zwolinska A, et al. Simple method for determining human serum 2,2-diphenyl-1-picryl-hydrazyl (DPPH) radical scavenging activity - possible application in clinical studies on dietary antioxidants. Clin Chem Lab Med. 2008;46(3):342-9. PMID: 18254708; doi: 10.1515/CCLM.2008.062.

17. Obanda M, Owuor PO, Taylor SJ. Flavanol composition and caffeine content of green leaf as quality potential indicators of Kenyan black teas. J Sci Food Agric. 1997; 74(2):209-15. doi: 10.1002/(SICI) 10970010(199706)74:2<209::AID-JSFA789>3.0.CO;2-4.

18. Pellegrini N, Chiavaro E, Gardana C, et al. Effect of different cooking methods on color, phytochemical concentration, and antioxidant capacity of raw and frozen brassica vegetables. J Agric Food Chem. 2010;58(7):4310-21. PMID: 20218674; doi: 10.1021/jf904306r.

19. Zhang D, Hamauzu Y. Phenolics, ascorbic acid, carotenoids and antioxidant activity of broccoli and their changes during conventional and microwave cooking. Food Chem. 2004;88(4):503-9. doi: 10.1016/j. foodchem.2004.01.065.

20. Bernhardt S, Schlich E. Impact of different cooking methods on food quality: Retention of lipophilic vitamins in fresh and frozen vegetables. J Food Engin. 2006;77(2):327-33. doi: 10.1016/j.jfoodeng.2005.06.040.

21. Volden J, Borge Gl, Hansen M, Bengtsson GB, Wicklund T. Processing (blanching, boiling, steaming) effects on the content of glucosinolates and antioxidant-related parameters in cauliflower (Brassica oleracea L. ssp botrytis). LWT-Food Science and Technology. 2009;42(1):63-73. doi: 10.1016/j.lwt.2008.05.018.

22. dos Reis LCR, de Oliveira VR, Hagen MEK, et al. Carotenoids, flavonoids, chlorophylls, phenolic compounds and antioxidant activity in fresh and cooked broccoli (Brassica oleracea var. Avenger) and cauliflower (Brassica oleracea var. Alphina F1). LWT-Food Science and Technology. 2015;63(1):177-83. doi: 10.1016/j.Iwt.2015.03.089.

23. Girgin N, El Nehir S. Effects of cooking on in vitro sinigrin bioaccessibility, total phenols, antioxidant and antimutagenic activity of cauliflower (Brassica oleraceae L. var. Botrytis). J Food Composit Anal. 2015;37:11927. doi: 10.1016/j.jfca.2014.04.013.

24. Park JH, Park YK, Park E. Antioxidative and antigenotoxic effects of garlic (Allium sativum L.) prepared by different processing methods. Plant Foods Hum Nutr. 2009;64(4):244-9. PMID: 19711184; doi: 10.1007/ s11130-009-0132-1.

25. loku K, Aoyama Y, Tokuno A, et al. Various cooking methods and the flavonoid content in onion. J Nutr Sci Vitaminol (Tokyo). 2001;47(1):7883. PMID: 11349895; doi: 10.3177/jnsv.47.78. 
26. Rohn S, Buchner N, Driemel G, Rauser M, Kroh LW. Thermal degradation of onion quercetin glucosides under roasting conditions. J Agric Food Chem. 2007;55(4):1568-73. PMID: 17263552; doi: 10.1021/jf063221i.

27. Lee SU, Lee JH, Choi SH, et al. Flavonoid content in fresh, homeprocessed, and light-exposed onions and in dehydrated commercial onion products. J Agric Food Chem. 2008;56(18):8541-8. PMID: 18759442; doi: 10.1021/jf801009p.

28. Harris S, Brunton N, Tiwari U, Cummins E. Human exposure modelling of quercetin in onions (Allium cepa L.) following thermal processing. Food Chem. 2015;187:135-9. PMID: 25977008; doi: 10.1016/j. foodchem.2015.04.035.

29. Li L, Pegg RB, Eitenmillera RR, Chun JY, Kerrihardc AL. Selected nutrient analyses of fresh, fresh-stored, and frozen fruits and vegetables. J Food Composit Anal. 2017;9(4):8-17. doi: 10.1016/j.jfca.2017.02.002.

30. Patras A, Tiwari BK, Brunton NP. Influence of blanching and low temperature preservation strategies on antioxidant activity and phytochemical content of carrots, green beans and broccoli. LWTFood Science and Technology. 2011:44(1):299-306. doi: 10.1016/j. Iwt.2010.06.019.

31. Alanís-Garza PA, Becerra-Moreno A, Mora-Nieves JL, MoraMora JP, Jacobo-Velázquez DA. Effect of industrial freezing on the stability of chemopreventive compounds in broccoli. Int J Food Sci Nutr. 2015;66(3):282-88. PMID: 25690928; doi: 10.3109/09637486.2015.1007451.

32. Murcia MA, Jiménez AM, Martínez-Tomé M. Vegetables antioxidant losses during industrial processing and refrigerated storage. Food Res Int. 2009;42(8):1046-52. doi: 10.1016/j.foodres.2009.04.012.

33. Volden J, Bengtsson GB, Wicklund T. Glucosinolates, L-ascorbic acid, total phenols, anthocyanins, antioxidant capacities and colour in cauliflower (Brassica oleracea L. ssp botrytis); effects of long-term freezer storage. Food Chem. 2009;112(4):967-76. doi: 10.1016/j. foodchem.2008.07.018.

34. Ninfali P, Bacchiocca M. Polyphenols and antioxidant capacity of vegetables under fresh and frozen conditions. J Agric Food Chem. 2003;51 (8):2222-6. PMID: 12670160; doi: 10.1021/jf020936m.

35. Miglio C, Chiavaro E, Visconti A, Fogliano V, Pellegrini N. Effects of different cooking methods on nutritional and physicochemical characteristics of selected vegetables. J Agric Food Chem. 2008;56(1):139-47. PMID: 18069785; doi: 10.1021/jf072304b.

\section{Authors' contributions:}

Experimental design: Illker Durak, Nazlı Seda Durak Kılıçaslan

Biochemical analysis and performing the experiment: Hikmet Can

Çubukçu, Nazlı Seda Kıııçaslan, IIIker Durak

Statistical analysis: Hikmet Can Çubukçu

Writing the manuscript: Hikmet Can Çubukçu, Illker Durak

\section{The abstract of this study was presented at the $29^{\text {th }}$ National}

Biochemistry Congress of Turkey (October 27, 2018)

\section{Sources of funding: None}

Conflict of interests: None

Date of first submission: March 8, 2019

Last received: March 8, 2019

Accepted: August 6, 2019

\section{Address for correspondence:}

Hikmet Can Çubukçu

Maresal Cakmak State Hospital

Department of Medical Biochemistry, Biochemistry Laboratory

25070 Palandöken, Erzurum, Turkey

Tel. + 904423172264

E-mail: hikmetcancubukcu@gmail.com 